This article was downloaded by: [The University of Manchester]

On: 07 January 2012, At: 09: 31

Publisher: Psychology Press

Informa Ltd Registered in England and Wales Registered Number: 1072954

Registered office: Mortimer House, 37-41 Mortimer Street, London W1T 3J H, UK

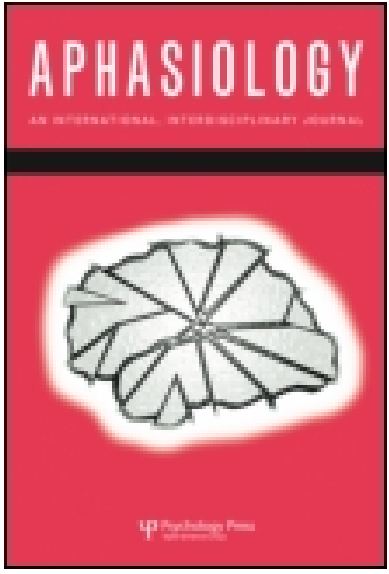

\title{
Aphasiology
}

Publication details, including instructions for authors and subscription information:

http:// www. tandfonline.com/loi/ paph20

\section{Repetition priming of picture naming in semantic aphasia: The impact of intervening items}

\author{
Maya Soni ${ }^{a}$, Matthew A. Lambon Ralph ${ }^{a} \&$ Anna M. Woollams \\ a \\ ${ }^{a}$ Neuroscience and Aphasia Research Unit, University of \\ Manchester, Manchester, UK
}

Available online: 05 Oct 2011

To cite this article: Maya Soni, Matthew A. Lambon Ralph \& Anna M. Woollams (2012): Repetition priming of picture naming in semantic aphasia: The impact of intervening items, Aphasiology, 26:1, 44-63

To link to this article: http:// dx.doi.org/ 10.1080/ 02687038.2011.602302

\section{PLEASE SCROLL DOWN FOR ARTICLE}

Full terms and conditions of use: http://www.tandfonline.com/page/terms-andconditions

This article may be used for research, teaching, and private study purposes. Any substantial or systematic reproduction, redistribution, reselling, loan, sub-licensing, systematic supply, or distribution in any form to anyone is expressly forbidden.

The publisher does not give any warranty express or implied or make any representation that the contents will be complete or accurate or up to date. The accuracy of any instructions, formulae, and drug doses should be independently verified with primary sources. The publisher shall not be liable for any loss, actions, claims, proceedings, demand, or costs or damages whatsoever or howsoever caused arising directly or indirectly in connection with or arising out of the use of this material. 


\title{
Repetition priming of picture naming in semantic aphasia: The impact of intervening items
}

\author{
Maya Soni, Matthew A. Lambon Ralph, and Anna M. Woollams
}

Neuroscience and Aphasia Research Unit, University of Manchester, Manchester, UK

\begin{abstract}
Background: We present an experiment that explores the nature of repetition priming of picture naming in a group of semantic stroke aphasic patients. The study was designed to extend previous investigations of repetition priming effects among other stroke aphasic patients and patients with semantic dementia. This work builds on previous work with semantic aphasic patients that shows enhanced picture-naming performance due to correct phonemic cues.

Aims: To assess the extent to which semantic control deficits observed during semantic aphasic patients' picture naming are resolved by prior exposure to an identical stimulus, and to determine the optimal lag between prime and target to maximise naming success. Methods \& Procedures: The procedure was carried out with five stroke patients who had all failed verbal and picture versions of tests of semantic association, revealing difficulties with manipulation of semantic information, and their performance was compared to five age- and education-matched controls. A total of 180 pictures to be named were presented individually on a computer screen in two sessions at least a week apart, with half preceded by an identical item in session one and the other half preceded by an identical item in session two. Three lags $(0,1$, and 7 items intervening) were embedded in the pseudo-random structure such that it was unpredictable whether the next trial would be a repeat or not. Outcomes \& Results: Considerable repetition priming was observed in this semantic aphasic patient group, bringing their performance up to control level at lag 0 . Priming with a very short lag between prime and target ( $0-1$ item) significantly reduced latency. Accuracy was significantly increased and semantic errors decreased with up to seven intervening items. Controls also benefited from repetition priming, but showed little variation in latency, accuracy or errors over this range of short lags.

Conclusions: For patients with problems manipulating semantic information, repetition priming was an effective way to boost naming performance, although increasing the number of intervening items had a progressively detrimental effect. The observed repetition priming effects are interpreted within a connectionist model of speech production.
\end{abstract}

Keywords: Repetition priming; Picture naming; Stroke aphasia; Semantic memory; Executive control; Speech production.

Behavioural facilitation by a previous encounter is one of the most powerful and widely studied effects in psycholinguistics (Francis, Corral, Jones, \& Saenz, 2008; Stark \& McClelland, 2000; Wheeldon \& Monsell, 1992), and occurs across multiple

Address correspondence to: Anna M. Woollams, Neuroscience and Aphasia Research Unit, School of Psychological Sciences, Zochonis Building, University of Manchester, Brunswick Street, Manchester, M13 9PL, UK. E-mail: anna.woollams@manchester.ac.uk

(C) 2012 Psychology Press, an imprint of the Taylor \& Francis Group, an Informa business http://www.psypress.com/aphasiology

http://dx.doi.org/10.1080/02687038.2011.602302 
tasks (Cumming, Graham, \& Patterson, 2006; Howard, Patterson, Franklin, OrchardLisle, \& Morton, 1985; Vitkovitch, Rutter, \& Read, 2001). Repetition also forms the basis for much impairment-directed speech and language therapy for deficits such as anomia seen among aphasic patients (Fillingham, Sage, \& Lambon Ralph, 2005; Helmick \& Wipplinger, 1975; Hengst, Duff, \& Dettmer, 2010; Nickels, 2002; Raymer \& Ellsworth, 2002), although experimental investigations of repetition priming (RP) among patients have been relatively rare (e.g., Cumming et al., 2006; Howard, Hickin, Redmond, Clark, \& Best, 2006; Martin \& Laine, 2000).

Semantic aphasia (SA) is a multimodal semantic deficit characterised by a failure of control processes rather than damage to central semantic representations (Jefferies \& Lambon Ralph, 2006; Jefferies Patterson, \& Lambon Ralph, 2008; Noonan, Jefferies, Corbett, \& Lambon Ralph, 2010; Soni et al., 2009). Anomia is a common feature of SA that can be alleviated by the provision of correct phonemic cues (Jefferies et al., 2008; Noonan et al., 2010; Soni et al., 2009). Previous work showing substantial cueing effects in semantic aphasia suggests that this patient group should be particularly receptive to repetition priming in picture naming. Here we consider for the first time the extent and longevity of repetition priming effects in a small case-series of SA patients.

Work with SA patients in the verbal domain has highlighted the impact of both correct and misleading phonemic cues upon picture naming (Jefferies \& Lambon Ralph, 2006; Jefferies et al., 2008; Noonan et al., 2010; Soni et al., 2009); other studies have focused more on comprehension (Noonan et al., 2010) and the non-verbal domain (Corbett, Jefferies, \& Lambon Ralph, 2009). Altogether, tests indicate a central amodal semantic impairment in SA resulting from poor semantic control, namely an impaired ability to harness semantic information appropriate to the task in hand. SA patients' performance provides a demonstration of the importance of semantic control in allowing effective use of intact semantic representations.

Cued naming experiments where pictures and single phonemes are presented simultaneously have helped to illustrate the semantic control difficulties of SA patients, and also to distinguish them from other groups with central semantic impairment such as semantic dementia (SD). Using cues that were either correct initial phonemes or initial phonemes from category co-ordinates or associates, it was found that correct cues significantly improved picture naming in SA patients (Jefferies et al., 2008; Noonan et al., 2010; Soni et al., 2009), in contrast with SD patients in a similar experiment who gained no significant benefit from correct cueing (Jefferies et al., 2008). Phonemic cues were able to enhance activation of targets, showing that poor semantic control can be ameliorated, allowing SA patients to access semantic representations that still exist but are hard to reach, whereas correct cues were ineffective for SD patients whose core representations are degraded. Further work has shown that SA responses to miscue trials were significantly less accurate than with correct cues, with a stronger and more reliable effect from co-ordinate than associate miscues (Noonan et al., 2010; Soni et al., 2009; Soni, Lambon Ralph, \& Woollams, 2011).

Given that a semantic control deficit leads to heightened sensitivity to cueing in SA patients, the question arises: How well would they prime from repeated stimuli? This can be seen as an extension of the correct cueing paradigm: instead of merely giving the initial phoneme, the entire name is elicited on the priming trial and then again on a subsequent trial. An important component of repetition priming in normal populations is that, as well as an effect on accuracy, there is a concomitant benefit to RT: primed items are produced significantly more quickly than unprimed (Lachman \& Lachman, 1980; Mitchell \& Brown, 1988; Wheeldon \& Monsell, 1992). Although 
there can be methodological difficulties when measuring latency in patients, reaction time measures have been used to quantify repetition priming effects in other patient groups (Bird, Lambon Ralph, Patterson, \& Hodges, 2000; Cumming et al., 2006), hence reaction times were measured in the present work in addition to accuracy and error types.

Although picture naming has been used as a priming task in studies with one or two patients in the contextual priming procedure, where several items are presented in an array (Laine \& Martin, 1996; Martin \& Laine, 2000; Renvall, Laine, Laakso, \& Martin, 2003; Renvall, Laine, \& Martin, 2007), repetition priming of single item picture naming has not been explored using a case-series approach, nor has it been explored with semantic aphasic patients. Furthermore, in the contextual priming procedure no feedback was given as to the correctness of the naming responses on priming trials, and the presence of multiple items may have obscured the link between picture and name for each individual item. Previous investigations of repetition priming among groups of aphasic patients have used either a lexical decision task throughout (Bird et al., 2000; Cumming et al., 2006) or WPM in the priming trials (Howard et al., 2006). In the current study the production task of single item picture naming with feedback was used for both the prime and target trials, as this procedure ensures both activation of an item's correct semantic representation and strengthening of the mapping from concept to phonological form, thus maximising the potential for repetition priming effects.

Previous considerations of RP effects among aphasic patients have suggested that the number of intervening items, or lag, is a crucial factor. In Cumming et al. (2006) a lexical decision task was used with SD patients, with variable lag between prime and target $(0,3,9$, or 23 items intervening). Knowledge of words was manipulated by using a word set previously tested on other SD patients and classified as "known" or "degraded". All types of words showed RP relative to nonwords (a lexicality effect), but the knowledge of words also interacted with lag: known words did show priming but degraded words showed "hyperpriming" (greater than expected RP relative to control performance) at the shorter lags ( 0 and 3 intervening items) but not longer (9 and 23). Hence it appears that the hyperpriming effect for degraded words decays relatively quickly to match the smaller priming effect shown for known words.

In addition to SD, stroke aphasic patients have also exhibited RP effects: both those with semantic impairments, for whom semantic errors are proportionally greatest in naming, and those with "post-semantic" impairments, whose primary error type is phonological (Howard et al., 2006). Howard et al. used the priming task of spoken word to picture matching (WPM), achieved by pointing at an item in an array on a computer screen. Patients did not produce the item name (although they did hear it in spoken WPM), nor did they receive feedback on the performance during the task. All patients showed some RP effects, but lag was again seen to have a differential effect: patients who were considered to have a semantic impairment only show RP at short lags (2-3 minutes) while those with a post-semantic impairment showed facilitation at both short and long lags (up to 25 minutes). However, the post-semantic group performed significantly better than the semantically impaired group on spoken, written, and concrete WPM, allowing the interpretation that poorer processing of primes accounted for the briefer priming effects in patients with greater semantic impairment. Furthermore, the patients never produced the name themselves but respond by pointing, minimising priming of meaning to form mappings. In this study we maximised the likelihood of such priming by ensuring all patients produced the correct picture name, whether spontaneously or via their good repetition skills. 
Given that RP is observed in semantically impaired groups, and that lag has been shown to have a differential effect in semantically impaired groups, what lag would maximise priming effects for SA patients? Given their semantic control impairment, it seemed most likely that short lags would be most effective, with very few intervening items to disrupt or obscure the activation produced by the prime: thus lags of 0,1 , and 7 items were selected. The use of both lags 0 and 1 was to attempt to delineate between a true facilitation from RP (lag 1) and an effect which could be gained merely by residual phonological activation from the previous trial (lag 0 ); it could also reveal any possible refractory effects of having produced an item's name on the immediately preceding trial (lag 0).

\section{METHOD}

\section{Participants}

Five SA patients were recruited from stroke clubs or recommended by speech and language services in Greater Manchester, UK. They were a subset of those reported in other work on this patient group (Jefferies, Baker, Doran, \& Lambon Ralph, 2007; Jefferies \& Lambon Ralph, 2006; Jefferies et al., 2008; Soni et al., 2009). Patients were enrolled if they failed both word and picture versions of semantic association tests such as the Camel and Cactus Test (CCT; Bozeat, Lambon Ralph, Patterson, $\&$ Hodges, 2000) and/or the Pyramids and Palm Trees Test or (PPT; Howard \& Patterson, 1992). Each patient had a chronic impairment from a CVA at least a year previous to the current study. Four were diagnosed with transcortical sensory aphasia (TSA) or anomic aphasia, with poor comprehension, fluent speech, and good repetition. Patient BB had less-fluent speech in addition to impaired comprehension. Table 1 includes biographical details, some details of lesion and aphasia type.

\section{Background neuropsychology and semantic testing}

Patients were tested on forward and backwards digit span (Wechsler, 1997), the Visual Object and Space Perception (VOSP) battery (Warrington \& James, 1991), and the Coloured Progressive Matrices test of non-verbal reasoning (Raven, 1962). Executive skill and attention were tested with the Wisconsin Card Sorting test (Milner, 1963; Stuss et al., 2000), the Brixton Spatial Rule Attainment task (Burgess \& Shallice, 1997), and Elevator Counting (with and without distraction) from the Test of

TABLE 1

SA patients' biographical details, lesion type, and patterns of co-occurrence

\begin{tabular}{lllccccl}
\hline Patient & Age & Sex & $\begin{array}{c}\text { Education } \\
\text { leaving age }\end{array}$ & $\begin{array}{c}\text { Years } \\
\text { since CVA }\end{array}$ & $\begin{array}{c}\text { Frontal } \\
\text { damage }\end{array}$ & $\begin{array}{c}\text { Temporo parietal } \\
\text { damage }\end{array}$ & Aphasia diagnosis \\
\hline $\mathrm{HN}$ & 77 & $\mathrm{M}$ & 15 & 2 & $\times$ & $\checkmark$ & Anomic/TSA \\
$\mathrm{PG}^{*}$ & 63 & $\mathrm{M}$ & 18 & 8 & $\checkmark$ & $\mathrm{w}$ & TSA \\
$\mathrm{SC}$ & 80 & $\mathrm{M}$ & 16 & 8 & $\times$ & $\checkmark$ & Anomic/TSA \\
$\mathrm{BB}$ & 59 & $\mathrm{~F}$ & 16 & 6 & $\checkmark$ & $\checkmark$ & Mixed transcortical \\
$\mathrm{ME}$ & 40 & $\mathrm{~F}$ & 16 & 9 & $\times$ & $\checkmark$ & TSA \\
\hline
\end{tabular}

Patients are arranged in order of naming scores in the 64-item battery (Bozeat et al., 2000).

$\mathrm{w}=$ damage confined to white matter immediately underlying cortex.

* = no scan available. Description of lesion: L frontal \& capsular. 
TABLE 2

Background neuropsychological assessment of SA patients

\begin{tabular}{lccrrrrrr}
\hline Task/test & Max & Normal cut-off $^{\alpha}$ & $H N$ & $P G$ & $S C$ & $B B$ & ME & Mean \\
\hline VOSP dot counting & 10 & 8 & 8 & $\mathbf{5}$ & 10 & 10 & $\mathbf{3}$ & $\mathbf{7 . 2}$ \\
VOSP position discrimination & 20 & 18 & 19 & 20 & $\mathbf{1 7}$ & 18 & $\mathbf{1 5}$ & $\mathbf{1 7 . 8}$ \\
VOSP number location & 10 & 7 & 9 & 9 & 10 & 8 & $\mathbf{2}$ & $\mathbf{7 . 6}$ \\
VOSP cube analysis & 10 & 6 & $\mathbf{4}$ & 10 & 9 & $\mathbf{2}$ & $\mathbf{4}$ & $\mathbf{5 . 8}$ \\
Raven's coloured matrices (percentiles) & - & - & 20 & 50 & 50 & 50 & $<\mathbf{5}$ & 35.0 \\
WCST (number of categories) & 6 & $1 \gamma$ & 6 & $\mathbf{0}$ & 6 & 1 & $\mathbf{0}$ & 2.6 \\
Brixton spatial anticipation (correct) & 54 & 28 & 28 & $\mathbf{2 6}$ & $\mathbf{2 5}$ & $\mathbf{2 3}$ & $\mathbf{1 1}$ & $\mathbf{2 2 . 6}$ \\
TEA counting without distraction & 7 & 6 & 7 & $\mathbf{0}$ & 7 & $\mathbf{4}$ & 7 & $\mathbf{5 . 0}$ \\
TEA counting with distraction & 10 & 3 & 9 & 3 & $\mathbf{1}$ & $\mathbf{0}$ & 9 & 4.4 \\
Digit span forwards & - & 5 & 6 & 6 & 6 & 5 & 6 & 5.8 \\
Digit span backwards & - & 2 & 2 & 2 & 2 & $\mathbf{0}$ & 3 & $\mathbf{1 . 8}$ \\
PALPA word repetition & 80 & 80 & $\mathbf{6 9}$ & $\mathbf{7 3}$ & $\mathbf{7 8}$ & $\mathbf{7 7}$ & 80 & $\mathbf{7 5 . 4}$ \\
Picture PPT & 52 & 48.4 & $\mathbf{3 5}$ & $\mathbf{4 2}$ & 50 & $\mathbf{4 1}$ & $\mathbf{2 9}$ & $\mathbf{3 9 . 4}$ \\
Word PPT & 52 & 48.9 & $\mathbf{4 4}$ & $\mathbf{4 3}$ & 51 & $\mathbf{3 5}$ & $\mathbf{3 9}$ & $\mathbf{4 2 . 4}$ \\
Synonym judgement & 96 & 90.1 & $\mathbf{7 0}$ & $\mathbf{6 9}$ & $\mathbf{7 1}$ & $\mathbf{6 3}$ & $\mathbf{8 1}$ & $\mathbf{7 0 . 8}$ \\
Letter fluency & - & 21.8 & $\mathbf{1 9}$ & $\mathbf{2}$ & 24 & $\mathbf{0}$ & $\mathbf{1 4}$ & $\mathbf{9 . 5 6}$ \\
Category fluency & - & 62.7 & 63 & $\mathbf{4}$ & $\mathbf{1 7}$ & $\mathbf{1 3}$ & $\mathbf{2 5}$ & $\mathbf{2 4 . 4}$ \\
64 Item Picture Naming & 64 & 59.1 & $\mathbf{5 0}$ & $\mathbf{4 6}$ & $\mathbf{2 8}$ & $\mathbf{1 0}$ & $\mathbf{5}$ & $\mathbf{2 7 . 8}$ \\
64 Item Spoken Word-picture & 64 & 62.7 & $\mathbf{5 0}$ & $\mathbf{5 8}$ & $\mathbf{5 9}$ & $\mathbf{5 4}$ & $\mathbf{5 0}$ & $\mathbf{5 4 . 4}$ \\
Matching & & & & & & & & \\
64 Item Picture CCT & 64 & 52.7 & 54 & $\mathbf{4 4}$ & $\mathbf{4 6}$ & $\mathbf{3 8}$ & $\mathbf{1 3}$ & $\mathbf{3 9 . 0}$ \\
64 Item Word CCT & 64 & 56.6 & $\mathbf{5 4}$ & $\mathbf{4 0}$ & $\mathbf{5 6}$ & $\mathbf{3 0}$ & $\mathbf{3 4}$ & $\mathbf{4 2 . 8}$ \\
\hline
\end{tabular}

Patients are arranged in order of naming scores in the 64-item battery (Bozeat et al., 2000).

${ }^{\alpha}$ For semantic tests, this represents the control mean $-2 S D$.

${ }^{\gamma}$ Cut-off for 50-74-year-olds (regardless of educational level).

All impaired scores are shown in bold.

$\mathrm{NT}=$ Not taken.

Everyday Attention (Robertson, Ward, \& Ridgeway, 1993). Semantic skills were tested using a number of assessments. For example, tests of semantic association included the Pyramids and Palm Trees Test (PPT; Howard \& Patterson, 1992) and Camel and Cactus Test (CCT; Bozeat et al., 2000), where participants have to decide which of two (PPT) or four (CCT) items is most associated with a target, e.g. pyramid with a pine tree or a palm tree. Both PPT and CCT were assessed with word and picture versions. CCT forms part of a 64-item semantic battery that also tested spoken picture naming and spoken word to picture matching on the same items. Other semantic tests comprised synonym judgement (Jefferies, Patterson, Jones, \& Lambon Ralph, 2009), category fluency (animals, birds, fruit, household items, tools, and vehicles) and letter fluency (letters F, A, and S). As is immediately apparent from Table 2, all patients showed significant impairments across a variety of tests tapping semantic knowledge.

\section{Control participants}

Five control participants were drawn from a pool of volunteers. Each one was individually matched with a patient on age and education leaving age. All controls had normal or corrected to normal vision and no history of neurological damage. 


\section{Stimuli}

A total of 180 black and white line drawings of common natural and man-made objects were selected from standard picture sets (Snodgrass \& Vanderwart, 1980; Szekely et al., 2003). The stimuli were then divided into three lists (one for each lag condition) matched on name agreement (mean $=0.98 ; S D=0.03$, from the International Picture Naming Project (IPNP): Szekely et al., 2003), reaction time (mean $=871 \mathrm{~ms} ; S D=114 \mathrm{~ms}$, from IPNP: Szekely et al., 2003), number of syllables (mean $=1.53 ; S D=0.72$, from IPNP: Szekely et al., 2003), number of phonemes (mean $=4.03 ; S D=1.50$, from IPNP: Szekely et al., 2003), frequency $($ mean $=$ 3.23; $S D=1.43$, from CELEX lexical database: Baayen, Piepenbrock, \& Gulikers, 1995), AoA (overall mean $=2.07 ; S D=0.94$, from the MacArthur Communicative Development Inventory (CDI): Fenson et al., 1994) and visual complexity (mean = 16304 kilobytes (KB); $S D=8027 \mathrm{~KB}$, from IPNP: Szekely et al., 2003). Items and norms for each list plus matching statistics can be found in Appendices A to G. Each of the three lists was further divided into two sections (A and B) matched to each other on the same variables: this was to enable testing to take place over two sessions. If set A was repeated in session 1, then set B formed the "control" or unprimed items; this assignment was reversed on the second test occasion, hence all items were seen in each session but in different conditions.

\section{Procedure}

The experiment was presented using E-Prime (Schneider, Eschman, \& Zuccolotto, 2002) on a laptop, with participants sitting around $80 \mathrm{~cm}$ from the screen. Testing occurred over two sessions at a minimum of 2 weeks apart and was carried out in the patients' homes. There were three lag conditions, lag 0 (no intervening trials), lag 1 (one trial intervening), and lag 7 (seven trials intervening). Each item was seen in only one lag condition by each participant, but separate versions of the test were constructed such that all items appeared in all lag conditions, counterbalanced across the group. A number of semantically unrelated filler items were also included in each test in order to fill the number of trials intervening between lags. Each test consisted of 270 items to name (primes, targets, and fillers); the lags were interleaved in a varied manner so that the possibility of a repeated item was unpredictable. The task instructions noted that the pictures would appear on the screen one at a time; some might be shown more than once, but the participant should just try to name the picture in each case. The tester marked responses on a printed scoresheet and also recorded test sessions on a Sony IC digital recorder for later use in measuring reaction times. Reaction times, accuracy and error rate and type were measured; RTs were measured using Wavepad Sound Editor software (NCH, Swiftsound: www.nch.com.au/ wavepad).

At the onset of each picture an audio beep was played for $300 \mathrm{~ms}$, to serve as a marker for RT measurement. The picture appeared on screen for a maximum of $5 \mathrm{sec}-$ onds after which the screen went white; as soon as a correct response was given the tester initiated the next picture with a button press. If no response had been given the patient would be prompted for an answer; if no response was made or an error was produced, the tester would say the correct name and ask the participant to repeat it, ensuring that a correct production was obtained for all prime items. 


\section{RESULTS}

Dependent variables were analysed using an ANOVA with the within-participants factors of priming (2 levels: repeated and unrelated prime) and lag (3 levels: 0, 1, and 7), and the between-participants factor group ( 2 levels: patients and controls). Initial analyses revealed minimal effects of session, therefore all analyses are reported with data collapsed across this variable. ANOVAs were also carried out separately for each group with the same within-participants factors of priming and lag. Initially the results for the overall comparison ANOVA will be reported in order to ascertain whether patients behaved significantly differently to controls. ANOVAs for each group will then be reported, followed by planned comparisons to elucidate the details of any interactions. All probabilities reported for $t$-tests are one-tailed due to prior prediction of a facilitative effect of repetition priming. Most $F$-values reported are with sphericity assumed; however, Huynh-Feldt values are reported as appropriate to correct for violations of sphericity. Errors were defined according to the following classification: semantic, ${ }^{1}$ omission, ${ }^{2}$ or other. ${ }^{3}$

\section{Reaction times}

Only reaction times for correct responses were analysed. For the group comparison ANOVA on RTs there was a significant three-way interaction between lag, priming, and group, $F(1,8)=11.819 ; p=.006$, showing that priming had the greatest effect on patients at the shortest lag, diminishing swiftly with longer lags, whereas controls' performance remained more stable throughout, as can be seen in Figure 1. There was also a significant two-way interaction between lag and group, $F(2,13)=5.069 ; p=.031$, showing that, collapsed across priming, patient performance slowed at longer lags compared to similar performance across all lags by controls; the two-way interaction between priming and group was also marginally significant, $F(1,8)=5.062 ; p=.055$,

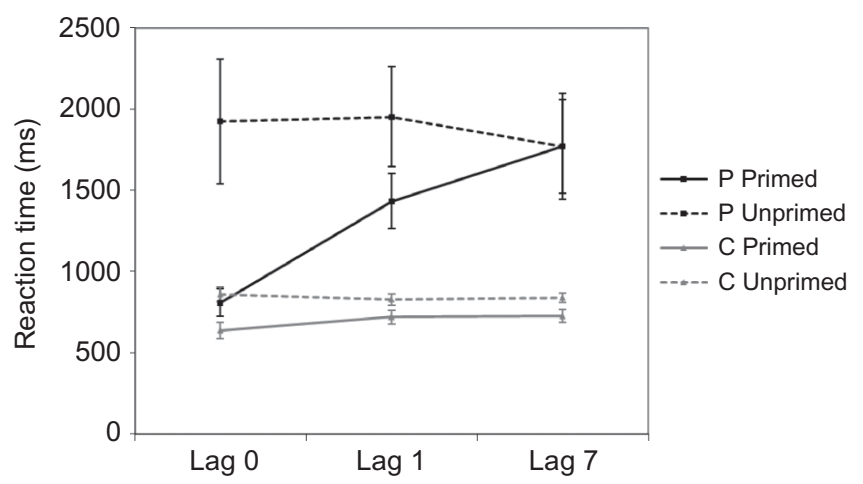

Figure 1. Reaction times for patients $(\mathrm{P})$ and controls $(\mathrm{C})$ according to priming and lag (error bars represent standard error).

\footnotetext{
${ }^{1}$ For example, co-ordinate, "kite" for BALloon; associate, "cup" for sPoon; superordinate, "animal" for TIGER; or correct circumlocutions, "you light them" for CANDLE.

2 No complete word answer, or "don't know".

${ }^{3}$ For example, incorrect circumlocutions, "you cook on them" for SINK; picture parts, "shirt" for MAN; phonological, "sky" for SKIS; visual "pen” for LIPSTICK; or unrelated/perseverative, "stairs" for PLATE.
} 
indicating a trend towards greater priming for patients than controls when lag conditions were collapsed. The main effect of group was significant, $F(1,8)=11.261 ; p=$ .01 , showing that patients responded significantly more slowly than controls (1609 ms vs 767 ms respectively).

In the ANOVA for patients' RTs there were significant main effects of priming, $F(1,4)=9.670 ; p=.036$, and lag, $F(2,8)=6.026 ; p=.025$, and an interaction between priming and lag, $F(1,4)=14.733 ; p=.018$, showing an effect of priming that decayed swiftly with increasing lag (see Figure 1). Planned comparisons revealed that for patients there were significant differences in RT at Lag $0, t(4)=3.552), p=.012$, and Lag 1, $t(4)=3.396 ; p=.014$, but not at Lag 7. In the ANOVA for controls there were main effects of priming, $F(1,4)=47.905 ; p=.002$, and lag, $F(2,8)=6.765$; $p=.019$, and an interaction between priming and lag, $F(2,8)=11.871 ; p=.004$, which appears to be driven by a larger priming effect at lag 0 . Planned comparisons revealed that there were significant differences in controls' RT between primed and unprimed items (see Figure 1) at Lag $0, t(4)=5.470 ; p=.003$, Lag $1, t(4)=9.204$; $p=.001$, and Lag 7, $t(4)=6.815 ; p=.001$, a continued effect of prior presentation throughout this range of lags.

\section{Accuracy}

The accuracy results revealed a three-way interaction between priming, lag, and group, $F(1,11)=4.654 ; p=.043$, showing that though patients' accuracy was raised to within the range shown by controls at lag 0 , as can be seen in Figure 2, this priming advantage declined sharply with more intervening trials. There were also significant two-way interactions between priming and group, $F(1,8)=12.656 ; p=.007$, showing that the patients responded more to priming than controls regardless of lag, and lag and group, $F(2,16)=9.067 ; p=.002$, showing that when priming conditions were collapsed, longer lags reduced patients' but not controls' accuracy. The main effect of group was significant, showing that patients' responses were significantly less accurate than controls' (.662 vs .975 , respectively).

In the group ANOVA for patients alone there were there were significant main effects of priming, $F(1,4)=16.973 ; p=.015$, and lag, $F(2,8)=9.107 ; p=.009$,

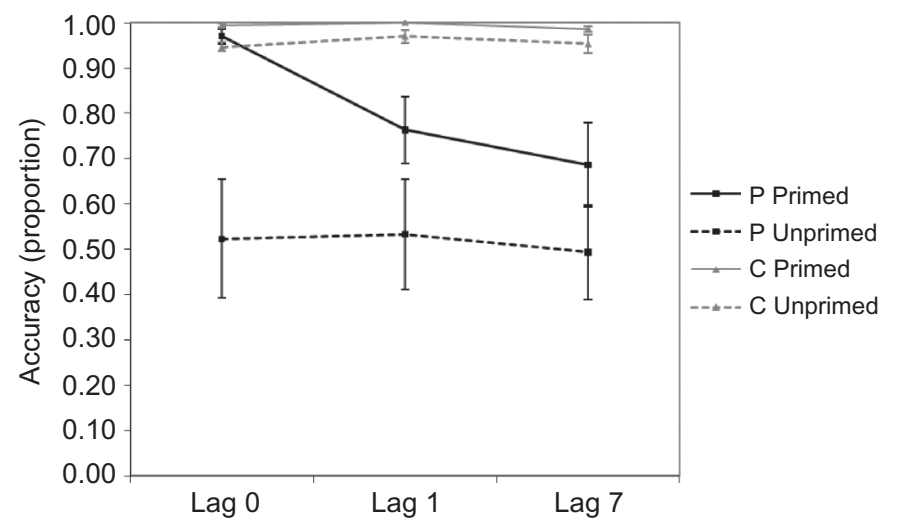

Figure 2. Accuracy for patients (P) and controls (C) according to priming and lag (error bars represent standard error). 
and an interaction between lag and priming, $F(2,8)=5.617 ; p=.030$, driven by the larger priming effect at lag 0 (see Figure 2). Planned comparisons showed that there were significant benefits from priming at lag $0, t(4)=3.520 ; p=.012$, lag $1, t(4)=$ $3.933 ; p=.009$, and lag $7, t(4)=4.302 ; p=.007$. In the ANOVA for controls there was a significant effect of priming, $F(1,4)=11.585 ; p=.027$, but not of lag, $F(2,8)=$ 2.250 , and no interaction, $F(2,8)=.344$. Although controls' accuracy was near ceiling throughout this range of lags (.95 or over in all conditions), planned comparisons showed a significant difference between primed and unprimed items (see Figure 5) at Lag $0, t(4)=4.176 ; p=.007$, Lag 1 was marginally significant, $t(4)=2.107 ; p=.052$, and Lag 7 also approached significance, $t(4)=1.533 ; p=.100$.

\section{Semantic errors ${ }^{4}$}

For semantic errors there was only a significant two-way interaction between priming and group, $F(1,8)=11.303 ; p=.01$, indicating that the priming effect was larger for patients than controls; see Figure 3 for performance of each group. The main effect of group was significant, $F(1,8)=9.729 ; p=.014$, showing that patients produced significantly more semantic errors than controls (.167 vs .018 respectively).

In the patients' ANOVA for semantic errors there was a significant main effect of priming, $F(1,4)=15.366 ; p=.017$; planned comparisons revealed that patients produced significantly fewer semantic errors with primed than unprimed items (see Figure 3) at $\operatorname{Lag} 0, t(4)=3.089 ; p=.019, \operatorname{Lag} 1, t(4)=2.580 ; p=.032$, and Lag 7, $t(4)=10.130 ; p=.001$. Being the reverse of the accuracy data, controls' semantic error rates were at floor in the primed condition and very low in the unprimed condition: nevertheless, there was a significant main effect of priming, $F(1,4)=11.497$; $p=.028$, and the main effect of lag approached significance, $F(2,8)=3.273 ; p=.092$. Planned comparisons showed that semantic error rates to primed targets were significantly lower than with unprimed items (see Figure 3 ) at Lag $0, t(4)=3.730 ; p=.010$,

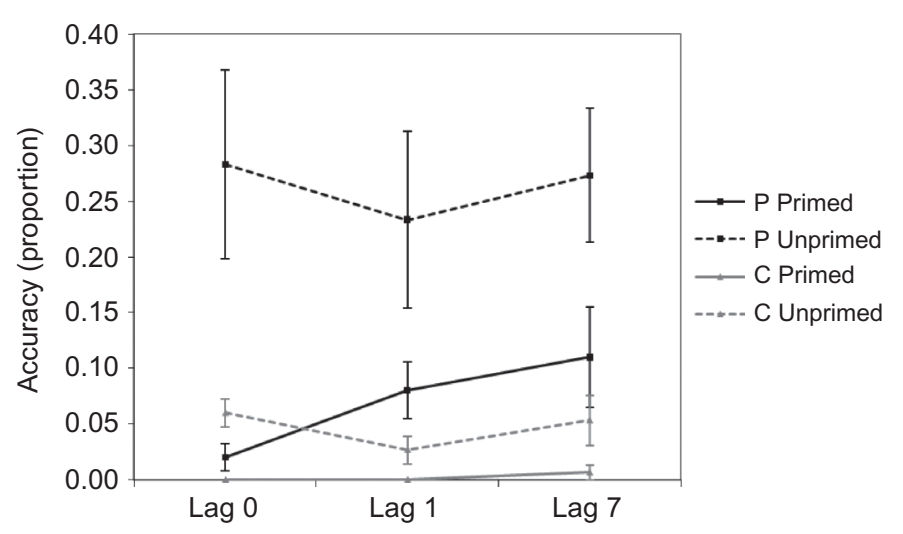

Figure 3. Semantic error rates as a proportion of all trials for patients $(\mathrm{P})$ and controls $(\mathrm{C})$ according to priming and lag (error bars represent standard error).

\footnotetext{
${ }^{4}$ There were no significant differences in omission rates or other errors, either in the overall comparison or in individual ANOVAs for each group.
} 
and Lag $1, t(4)=2.161 ; p=.049$, but lag 7 did not quite show a significant difference, $t(4)=1.484 ; p=.106$.

\section{DISCUSSION}

Patients' RTs with primed targets increased steeply with extra intervening items (lag $0=808 \mathrm{~ms}$; lag $1=1433 \mathrm{~ms}$; lag $7=1770 \mathrm{~ms}$ ); although still showing a significant priming effect at lag 1, primed and unprimed latency were identical by lag 7. Patients' unprimed latencies remained relatively stable (lag $0=1924 \mathrm{~ms}$; lag $1=1953 \mathrm{~ms}$; lag $7=1770 \mathrm{~ms}$ ), showing that the differences at each lag resulted from a progressive reduction in the effect of repetition priming (RP). Although significant main effects and an interaction were also seen for latency in control participants, the greater detail shown by planned comparisons demonstrated that controls maintained a latency benefit from priming across all lags in this range (primed vs unprimed latency: lag $0=$ 637 vs $859 \mathrm{~ms}$; lag $1=719$ vs $827 \mathrm{~ms}$; lag $7=724$ vs $838 \mathrm{~ms}$ ). These data show that compared with longer-lasting effects in controls, RP effects on latency in SA patients were quickly dissipated by additional intervening items. Although patients' accuracy retained a significant benefit from priming across all lags, this advantage declined with more intervening items (primed vs unprimed accuracy: lag $0=97 \%$ vs $52.3 \%$; lag $1=$ $76.3 \%$ vs $53.3 \%$; lag $7=68.7 \%$ vs $49.3 \%$ ), whereas controls' performance appeared to remain more stable for both primed and unprimed items (lag $0=99.3 \%$ vs $94.7 \%$; lag 1 $=100 \%$ vs $97 \%$; lag $7=98.7 \%$ vs $95.3 \%$ ) across this range of lags. Patients also showed an increase in semantic error rates with increasing lag, although primed semantic error rates remained significantly lower than unprimed (lag $0=2 \%$ vs $28.3 \%$; lag $1=8 \%$ vs $23.3 \%$; lag $7=11 \%$ vs $27.3 \%$ ). Concomitant with controls' high accuracy, semantic error rates were extremely low (primed vs unprimed semantic error rates: lag $0=0 \%$ vs $6 \%$; lag $1=0 \%$ vs $2.7 \%$; lag $7=0.7 \%$ vs $5.3 \%$ ): unlike the patient group there is little reduction in RP with increasing lag.

As can be seen from this summary the detrimental effect of increasing lag is mirrored in all variables for this group of SA patients. We hypothesise that the prime guides the semantic control system during subsequent target selection, but impaired semantic control allows the initial benefits of RP to be dissipated by the presentation of intervening items. It is likely that, with longer lags, the raised activations of other more recent though irrelevant intervening items are harder to inhibit when semantic control is impaired, leading to less-efficient name selection and reduced priming. This is particularly clear in the arguably more sensitive latency measure, where the benefit of prior presentation is entirely absent for patients by lag 7. Continuing raised activation of the primed items can be detected in the significantly higher accuracy and lower semantic error rates even at lag 7 , but the enhanced speed of processing induced by priming is more vulnerable when semantic control is impaired. In the control participants, who have intact semantic control, the effects of RP remain relatively stable across this series of short lags, although as with the patients, lag 0 produces the fastest, most accurate responses. The difference between impaired and control performance is most clear when comparing across longer lags: intervening items clearly cause far greater disturbance to RP in the patients' than the controls.

Other studies have shown that RP effects diminish over time in those with a semantic impairment, although these semantic deficits may originate from different functional and anatomical causes. Semantic dementia patients, who are known to have a semantic impairment resulting from degradation of core semantic representations 
due to anterior temporal lobe atrophy (Bozeat et al., 2000, 2003; Jefferies \& Lambon Ralph, 2006; Jefferies, Patterson, \& Lambon Ralph, 2006; Rogers et al., 2004), have also been found to show greater RP in a lexical decision task at short than long lags (Cumming et al., 2006), but only on "degraded" words: known words showed an improvement at both short and long lags. In Howard et al. (1985) stroke patients with various aphasia diagnoses showed an effect of RP on naming accuracy that declined to the level of unprimed performance after 30 items. In Howard et al. (2006) stroke aphasic patients with semantic impairment showed an effect of priming on naming accuracy at short but not long lags, compared with stroke aphasic patients without semantic impairment who benefited from priming at both short and long lags. Although the integrity of semantic control processes and the precise anatomical location of damage for the stroke patients in these studies are unknown, we would suggest that the reduction in RP effects over time observed in the present cohort of SA patients occurs due to their impaired semantic control resulting from frontal and temporo-parietal lesions (Soni et al., 2011).

Support for the interpretation of the reduction of the RP effect at increasing lags observed here in terms of semantic control deficits is given by reports of refractory effects among the same group, where patients show poorer accuracy when required to name semantically related relative to unrelated sets of items, particularly in rapid succession (Jefferies et al., 2007). Similar deficits are observed in the comprehension performance of other patients described as having refractory access disorders (Crutch \& Warrington, 2003, 2005; Warrington \& Cipolotti, 1996; Warrington \& Crutch, 2004). Although these studies observed increased inhibition due to semantic relatedness, whereas we observed a reduction in facilitation from repetition here, both effects can be attributed to increased susceptibility to competition from the semantic activation of intervening items as a result of impaired semantic control. Essentially, semantic control impairments mean that these patients are more vulnerable to the build-up of competition over time, either from the requirement to name semantically related items repeatedly in the case of refractory effects or from the presence of more intervening items in the present work.

Although we propose impaired semantic control to account for RP effects in our data, other potential explanations exist. In the current experiment pictures were named in both prime and target tasks, sometimes with no intervening trials. Howard et al. (1985) suggest that when target immediately follows prime, a kind of phonological "prompting" may be taking place, perhaps due to the information remaining in working memory. Wheeldon and Monsell (1992) further suggest that there could be an episodic memory trace, especially where priming and target tasks are identical. It could also be argued that, at lag 0 , due to our protocol of eliciting a correct production before proceeding to the next trial, a correct response is in fact merely repetition of the previous response rather than naming via word retrieval. However, due to the pseudorandom trial order, the nature of an individual trial was not predictable: any trial could have been primed 0,1 , or 7 trials previously, or indeed could be unprimed. Thus a strategy of repeating the previous response would seldom be successful, and would have resulted in a high level of perseverative errors, which did not in fact occur. We therefore argue that, even at lag 0 , responses represent naming via word retrieval triggered by viewing a picture, not repetition. Effects such as retention of information by working memory or an episodic memory trace cannot be ruled out by our data, indeed the heightened priming at lag 0 seen in both patient and control groups could indicate some retention in working memory, but we argue that continued effects on 
RT at lag 1 and on accuracy and error rates at lags 1 and 7 show true facilitation by priming in this patient group.

There are of course multiple potential loci for these RP effects within the picturenaming process: object recognition/identification, linking initial visual processing to a semantic representation; mapping between semantics and phonology, linking a concept to a phonological form; and production of that phonological form (Francis et al., 2008; Glaser, 1992; Humphreys, Riddoch, \& Quinlan, 1988; Morrison, Ellis, \& Quinlan, 1992; Wheeldon \& Monsell, 1992). In our task the pictured items were always overtly named in the priming trials (with or without assistance from the tester), which necessarily primes all stages from object recognition to name production, as was our intent in order to maximise priming.

Different studies have offered various hypotheses on the locus of RP. In Howard et al. (1985) several priming tasks were used with stroke aphasic patients: auditory and written word to picture matching and a semantic judgement task consisting of answering a yes/no question about the characteristics of an item (e.g., "Does a cow eat grass?"). None of these tasks involved production of the item's name by the patients, and the semantic judgement task made no connection between an item's picture and its name, requiring only an internal access to the meaning. Both auditory WPM and the semantic judgement task produced a facilitatory effect on naming up to 41 items later (around 20 minutes). The authors concluded that, because no overt production was required, these priming tasks improved subsequent naming performance by boosting target activations at the semantic level. Support for a semantic locus of RP effects in the SA patients we consider here is given by the refractory effects seen in picture naming in a similar group of patients (Jefferies et al., 2007). Both the reduced RP effects at longer lags observed in the current experiment and the increased difficulties of SA patients when naming blocks of semantically related items could be accounted for by increased competition at the semantic level.

In their study of RP using spoken word to picture-naming priming trials with stroke aphasic patients with and without semantic deficits, Howard et al. (2006) suggest that $\mathrm{RP}$ can also occur later in the word production process, for example during meaning to form mapping. They concluded that, for those with semantic deficits, lemma access is primed over short lags; for those who can access lemmas well they cite a longer-lasting boost in meaning to form mapping. Wheeldon and Monsell (1992) used both word reading and naming to definition as their priming tasks with normal participants, and found a consistent and long-lasting priming effect on naming. The lack of facilitation when the priming trial elicited a homophone of the target ruled out boosting phonological activation alone; priming of object identification alone was also ruled out, as their cross-modal priming tasks did not include pictures. Wheeldon and Monsell concluded that because all priming trials involve overt production of an item's name, their results could support an effect based on boosting semantic representations and/or meaning to form mapping.

Other evidence indicating a semantic component to RP is provided by observations that the effect declines more quickly in patients with more severe semantic impairment (Howard et al., 2006) or on items that are more semantically degraded (Cumming et al., 2006). In the current experiment it is clear that the SA patients can still reap benefits in terms of accuracy after seven intervening items, although the benefit accruing to latency has diminished by this point. We suggest that in connectionist models of learning and speech production (de Zubicaray, McMahon, Eastburn, Pringle, \& Lorenz, 2006; Foygel \& Dell, 2000; Hinton \& Shallice, 1991; McClelland \& Rumelhart, 
1987; Seidenberg \& McClelland, 1989; Stark \& McClelland, 2000), RP causes change in the connection weights between semantic units, or between semantic and phonological units, raising the activation of the target. When that item is presented again soon afterwards, residual activation makes name selection more efficient.

The current study was exploratory in nature and was not designed to determine the precise locus of RP effects. Although we favour an account of RP in SA patients in terms of facilitation at the semantic level or strengthened mapping between concept and form, it is possible that there may also be a boost to phonological representations or retention of information in working memory, particularly at lag 0 . Future research could use different tasks for prime and target trials to determine more precisely the locus of the RP effect observed here among patients with SA, and could explore the possibility that RP could provide more long-lasting benefits to word retrieval.

Manuscript received 8 February 2011

Manuscript accepted 6 June 2011

First published online 5 October 2011

\section{REFERENCES}

Baayen, R., Piepenbrock, R., \& Gulikers, L. (1995). The CELEX lexical database (Release 2). Philadelphia: University of Pennsylvania, Linguistic Data Consortium.

Bird, H., Lambon Ralph, M., Patterson, K., \& Hodges, J. (2000). The rise and fall of frequency and imageability: Noun and verb production in semantic dementia. Brain and Language, 73(1), 17-49.

Bozeat, S., Lambon Ralph, M., Graham, K., Patterson, K., Wilkin, H., Rowland, J., et al. (2003). A duck with four legs: Investigating the structure of conceptual knowledge using picture drawing in semantic dementia. Cognitive Neuropsychology, 20(1), 27-47.

Bozeat, S., Lambon Ralph, M., Patterson, K., \& Hodges, J. (2000). Non-verbal semantic impairment in semantic dementia. Neuropsychologia 38(9), 1207-1215.

Burgess, P., \& Shallice, T. (1997). The Hayling and Brixton Tests. Thurston, UK: Thames Valley Test Company.

Corbett, F., Jefferies, E., \& Lambon Ralph, M. (2009). Exploring multimodal semantic control impairments in semantic aphasia: Evidence from naturalistic object use. Neuropsychologia, 47(13), 2721-2731.

Crutch, S., \& Warrington, E. (2003). The organisation of semantic memory: Evidence from semantic refractory access dysphasia [Meeting Abstract]. Brain and Language, 87(1), 81-82.

Crutch, S., \& Warrington, E. (2005). Gradients of semantic relatedness and their contrasting explanations in refractory access and storage semantic impairments. Cognitive Neuropsychology, 22(7), 851-876.

Cumming, T., Graham, K., \& Patterson, K. (2006). Repetition priming and hyperpriming in semantic dementia. Brain and Language, 98(2), 221-234.

de Zubicaray, G., McMahon, K., Eastburn, M., Pringle, A., \& Lorenz, L. (2006). Classic identity negative priming involves accessing semantic representations in the left anterior temporal cortex. Neuroimage, 33(1), 383-390.

Fenson, L., Dale, P., Reznick, J., Bates, E., Thal, D., \& Pethick, S. (1994). Variability in early communicative development. Monographs of the Society for Research in Child Development, 59(5), 1-189.

Fillingham, J., Sage, K., \& Lambon Ralph, M. (2005). Further explorations and an overview of errorless and errorful therapy for aphasic word-finding difficulties: The number of naming attempts during therapy affects outcome. Aphasiology, 19(7), 597-614.

Foygel, D., \& Dell, G. S. (2000). Models of impaired lexical access in speech production. Journal of Memory and Language, 43, 182-216.

Francis, W., Corral, N., Jones, M., \& Saenz, S. (2008). Decomposition of repetition priming components in picture naming. Journal of Experimental Psychology-General, 137(3), 566-590.

Glaser, W. (1992). Picture naming [Review]. Cognition, 42(1-3), 61-105.

Helmick, J., \& Wipplinger, M. (1975). Effects of stimulus repetition on naming behaviour of an aphasic adult - clinical report. Journal of Communication Disorders, 8(1), 23-29.

Hengst, J. A., Duff, M. C., \& Dettmer, A. (2010). Rethinking repetition in therapy: Repeated engagement as the social ground of learning [Proceedings Paper]. Aphasiology, 24(6-8), 887-901. 
Hinton, G. E., \& Shallice, T. (1991). Lesioning an attractor network - Investigations of acquired dyslexia. Psychological Review, 98(1), 74-95.

Howard, D., Hickin, J., Redmond, T., Clark, P., \& Best, W. (2006). Re-visiting "semantic facilitation" of word retrieval for people with aphasia: Facilitation yes but semantic no. Cortex, 42(6), 946-962.

Howard, D., \& Patterson, K. (1992). Pyramids and palm trees: a test of semantic access from pictures and words. Bury St. Edmonds, UK: Thames Valley Test Company.

Howard, D., Patterson, K., Franklin, S., Orchard-Lisle, V., \& Morton, J. (1985). The facilitation of picture naming in aphasia. Cognitive Neuropsychology, 2(1), 49-80.

Humphreys, G., Riddoch, M., \& Quinlan, P. (1988). Cascade processes in picture identification. Cognitive Neuropsychology, 5(1), 67-103.

Jefferies, E., Baker, S., Doran, M., \& Lambon Ralph, M. (2007). Refractory effects in stroke aphasia: A consequence of poor semantic control. Neuropsychologia, 45(5), 1065-1079.

Jefferies, E., \& Lambon Ralph, M. (2006). Semantic impairment in stroke aphasia versus semantic dementia: A case-series comparison. Brain, 129(8), 2132-2147.

Jefferies, E., Patterson, K., Jones, R., \& Lambon Ralph, M. (2009). Comprehension of concrete and abstract words in semantic dementia. Neuropsychology, 23(4), 492-499.

Jefferies, E., Patterson, K., \& Lambon Ralph, M. (2006). The natural history of late-stage "pure" semantic dementia, 12(1), 1-14.

Jefferies, E., Patterson, K., \& Lambon Ralph, M. (2008). Deficits of knowledge versus executive control in semantic cognition: Insights from cued naming. Neuropsychologia, 46, 649-658.

Lachman, R., \& Lachman, J. (Eds.). (1980). Picture naming: Retrieval and activation of long term memory. Hillsdale, NJ: Lawrence Erlbaum Associates.

Laine, M., \& Martin, N. (1996). Lexical retrieval deficit in picture naming: Implications for word production models. Brain and Language, 53(3), 283-314.

Martin, N., \& Laine, M. (2000). Effects of contextual priming on impaired word retrieval. Aphasiology, 14(1), 53-70.

McClelland, J., \& Rumelhart, D. (1987). A distributed model of human learning and memory (Vol. 2, Psychological and biological models). Cambridge, MA: The Mit Press.

Milner, B. (1963). Effects of different brain lesions on card sorting - Role of frontal lobes. Archives of Neurology, 9(1), 90-97.

Mitchell, D. B., \& Brown, A. S. (1988). Persistent repetition in picture priming naming and its dissociation from recognition memory. Journal of Experimental Psychology - Learning Memory and Cognition, 14(2), 213-222.

Morrison, C., Ellis, A., \& Quinlan, P. (1992). Age of acquisition, not word-frequency, affects object naming, not object recognition. Memory and Cognition, 20(6), 705-714.

Nickels, L. (2002). Improving word finding: Practice makes (closer to) perfect? Aphasiology, 16(10-11), $1047-1060$.

Noonan, K., Jefferies, E., Corbett, F., \& Lambon Ralph, M. (2010). Elucidating the nature of deregulated semantic cognition in semantic aphasia: Evidence for the roles of prefrontal and temporoparietal cortices. Journal of Cognitive Neuroscience, 22, 1597-1613.

Raven, J. (1962). Coloured Progressive Matrices sets A, AB, B. London, UK: HK Lewis.

Raymer, A. M., \& Ellsworth, T. A. (2002). Response to contrasting verb retrieval treatments: A case study. Aphasiology, 16(10-11), 1031-1045.

Renvall, K., Laine, M., Laakso, M., \& Martin, N. (2003). Anomia treatment with contextual priming: A case study. Aphasiology, 17(3), 305-328.

Renvall, K., Laine, M., \& Martin, N. (2007). Treatment of anomia with contextual priming: Exploration of a modified procedure with additional semantic and phonological tasks. Aphasiology, 21(5), 499-527.

Robertson, I. H., Ward, T., \& Ridgeway, V. (1993). Test of Everyday Attention - Preliminary norms, reliability, and validity. Journal of Clinical and Experimental Neuropsychology, 15(3), 413-413.

Rogers, T., Lambon Ralph, M., Garrard, P., Bozeat, S., McClelland, J., Hodges, J., et al. (2004). Structure and deterioration of semantic memory: A neuropsychological and computational investigation. Psychological Review, 111(1), 205-235.

Schneider, W., Eschman, A., \& Zuccolotto, A. (2002). E-Prime user's guide. Pittsburgh, PA: Psychology Software Tools, Inc.

Seidenberg, M., \& McClelland, J. (1989). A distributed, developmental model of word recognition and naming [Review]. Psychological Review, 96(4), 523-568. 
Snodgrass, J., \& Vanderwart, M. (1980). A standardized set of 260 pictures: Norms for name agreement, image agreement, familiarity and visual complexity. Journal of Experimental Psychology: Human Learning and Memory, 6(2), 174-215.

Soni, M., Lambon Ralph, M., Noonan, K., Ehsan, S., Hodgson, C., \& Woollams, A. (2009). "L" is for tiger: Effects of phonological (mis)cueing on picture naming in semantic aphasia. Journal of Neurolinguistics, 22(6), 538-547.

Soni, M., Lambon Ralph, M. A., \& Woollams, A. M. (2011). "W" is for bath: Can associative errors be cued? Journal of Neurolinguistics, 24(4), 445-465.

Stark, C., \& McClelland, J. (2000). Repetition priming of words, pseudowords, and nonwords. Journal of Experimental Psychology-Learning Memory and Cognition, 26(4), 945-972.

Stuss, D., Levine, B., Alexander, M., Hong, J., Palumbo, C., Hamer, L., et al. (2000). Wisconsin Card Sorting Test performance in patients with focal frontal and posterior brain damage: Effects of lesion location and test structure on separable cognitive processes. Neuropsychologia, 38(4), 388-402.

Szekely, A., D’Amico, S., Devescovi, A., Federmeier, K., Herron, D., Iyer, G., et al. (2003). Timed picture naming: Extended norms and validation against previous studies. Behavior Research Methods Instruments \& Computers, 35(4), 621-633.

Vitkovitch, M., Rutter, C., \& Read, A. (2001). Inhibitory effects during object name retrieval: The effect of interval between prime and target on picture naming responses. British Journal of Psychology, 92, 483-506.

Warrington, E., \& Cipolotti, L. (1996). Word comprehension - The distinction between refractory and storage impairments. Brain, 119, 611-625.

Warrington, E., \& Crutch, S. (2004). A circumscribed refractory access disorder: A verbal semantic impairment sparing visual semantics. Cognitive Neuropsychology, 21(2-4), 299-315.

Warrington, E., \& James, M. (1991). Visual object and space perception. London, UK: Pearson Assessment.

Wechsler, D. (1997). The Wechsler Adult Intelligence Scale (3rd ed.). San Antonio, TX: Psychological Corporation.

Wheeldon, L., \& Monsell, S. (1992). The locus of repetition priming in spoken word production. Quarterly Journal of Experimental Psychology Section a - Human Experimental Psychology, 44(4), 723-761.

APPENDIX A

List 1 items and associated stimulus properties

\begin{tabular}{lllcccccc}
\hline Item & Set & $\begin{array}{c}\text { Name } \\
\text { agreement }\end{array}$ & Reaction time & Syllables & Phonemes & Frequency & AoA & $\begin{array}{c}\text { Visual } \\
\text { complexity }\end{array}$ \\
\hline anchor & $\mathrm{A}$ & 1 & 951 & 2 & 4 & 1.946 & 3 & 14010 \\
baby & $\mathrm{B}$ & 0.94 & 729 & 2 & 4 & 5.557 & 1 & 18598 \\
barrel & $\mathrm{A}$ & 0.98 & 882 & 2 & 4 & 3.091 & 3 & 18478 \\
beard & $\mathrm{A}$ & 0.96 & 1033 & 1 & 4 & 3.258 & 3 & 30362 \\
bed & $\mathrm{A}$ & 1 & 706 & 1 & 3 & 5.136 & 1 & 13761 \\
book & $\mathrm{A}$ & 1 & 656 & 1 & 3 & 6.075 & 1 & 8619 \\
boot & $\mathrm{B}$ & 0.9 & 869 & 1 & 3 & 3.689 & 1 & 8857 \\
bra & $\mathrm{B}$ & 1 & 917 & 1 & 3 & 1.946 & 3 & 11410 \\
broom & $\mathrm{A}$ & 1 & 821 & 1 & 4 & 2.197 & 1 & 11261 \\
button & $\mathrm{B}$ & 1 & 917 & 2 & 4 & 3.296 & 1 & 5726 \\
cannon & $\mathrm{A}$ & 1 & 1159 & 2 & 5 & 1.946 & 3 & 17678 \\
castle & $\mathrm{B}$ & 1 & 893 & 2 & 4 & 3.332 & 3 & 22746 \\
chair & $\mathrm{A}$ & 1 & 732 & 1 & 2 & 4.92 & 1 & 11238 \\
church & $\mathrm{B}$ & 0.96 & 988 & 1 & 3 & 5.215 & 1 & 34595 \\
comb & $\mathrm{A}$ & 1 & 717 & 1 & 3 & 1.792 & 1 & 28324 \\
cow & $\mathrm{A}$ & 0.94 & 1079 & 1 & 2 & 3.714 & 1 & 17300 \\
dinosaur & $\mathrm{A}$ & 0.98 & 1012 & 3 & 6 & 1.792 & 3 & 12393 \\
door & $\mathrm{B}$ & 1 & 719 & 1 & 2 & 5.958 & 1 & 12638 \\
\hline
\end{tabular}

(Continued) 
APPENDIX A

(Continued)

\begin{tabular}{|c|c|c|c|c|c|c|c|c|}
\hline Item & Set & $\begin{array}{c}\text { Name } \\
\text { agreement }\end{array}$ & Reaction time & Syllables & Phonemes & Frequency & $A o A$ & $\begin{array}{c}\text { Visual } \\
\text { complexity }\end{array}$ \\
\hline egg & A & 0.98 & 874 & 1 & 2 & 4.466 & 1 & 10440 \\
\hline fan & B & 0.98 & 865 & 1 & 3 & 2.89 & 3 & 35152 \\
\hline finger & B & 0.98 & 775 & 2 & 5 & 4.82 & 1 & 5370 \\
\hline flag & B & 1 & 847 & 1 & 4 & 3.296 & 2 & 9461 \\
\hline fork & A & 1 & 723 & 1 & 3 & 2.773 & 1 & 8818 \\
\hline genie & A & 0.98 & 1214 & 2 & 4 & 0.693 & 3 & 18559 \\
\hline glasses & B & 0.96 & 758 & 2 & 6 & 3.497 & 1 & 11525 \\
\hline goat & B & 0.96 & 972 & 1 & 3 & 3.367 & 3 & 15302 \\
\hline grapes & A & 0.9 & 849 & 1 & 5 & 0 & 2 & 23841 \\
\hline hammer & B & 1 & 724 & 2 & 4 & 2.485 & 1 & 9533 \\
\hline hat & A & 0.98 & 684 & 1 & 3 & 4.234 & 1 & 8732 \\
\hline hook & B & 1 & 919 & 1 & 3 & 3.638 & 3 & 10144 \\
\hline house & A & 0.98 & 745 & 1 & 3 & 6.409 & 1 & 18069 \\
\hline jar & B & 0.9 & 979 & 1 & 2 & 2.996 & 2 & 7664 \\
\hline kangaroo & A & 1 & 856 & 3 & 7 & 1.386 & 3 & 14555 \\
\hline kite & B & 1 & 796 & 1 & 3 & 1.792 & 3 & 17880 \\
\hline lion & A & 1 & 812 & 2 & 4 & 3.258 & 1 & 32267 \\
\hline mirror & B & 1 & 873 & 2 & 4 & 3.912 & 3 & 11938 \\
\hline mushroom & A & 1 & 746 & 2 & 6 & 2.639 & 3 & 8337 \\
\hline owl & B & 1 & 837 & 1 & 2 & 2.079 & 1 & 15316 \\
\hline pencil & A & 1 & 702 & 2 & 5 & 2.996 & 2 & 7899 \\
\hline pig & B & 1 & 855 & 1 & 3 & 3.784 & 1 & 10411 \\
\hline piggybank & A & 0.94 & 965 & 3 & 8 & 0 & 3 & 24489 \\
\hline pizza & A & 1 & 973 & 2 & 4 & 1.099 & 1 & 40526 \\
\hline plate & A & 0.94 & 1013 & 1 & 4 & 4.025 & 1 & 21533 \\
\hline queen & B & 1 & 931 & 1 & 4 & 3.989 & 3 & 11277 \\
\hline road & A & 0.92 & 925 & 1 & 3 & 5.521 & 3 & 26797 \\
\hline ruler & B & 1 & 779 & 2 & 4 & 2.944 & 3 & 10785 \\
\hline screwdriver & B & 1 & 1179 & 3 & 9 & 1.386 & 3 & 9051 \\
\hline shoe & A & 1 & 737 & 1 & 2 & 4.382 & 1 & 14105 \\
\hline skis & A & 0.95 & 1039 & 1 & 4 & 0 & 3 & 20764 \\
\hline sock & B & 1 & 712 & 1 & 3 & 2.944 & 1 & 8316 \\
\hline strawberry & B & 1 & 1052 & 3 & 8 & 1.946 & 2 & 16771 \\
\hline sword & B & 0.92 & 1084 & 1 & 3 & 2.89 & 3 & 10243 \\
\hline telescope & B & 0.98 & 1011 & 3 & 8 & 2.197 & 3 & 21547 \\
\hline tie & B & 0.98 & 758 & 1 & 2 & 3.555 & 3 & 19103 \\
\hline tomato & A & 0.98 & 962 & 3 & 6 & 2.708 & 3 & 8388 \\
\hline tree & B & 1 & 796 & 1 & 3 & 5.257 & 1 & 26074 \\
\hline umbrella & A & 1 & 738 & 3 & 7 & 2.708 & 3 & 15140 \\
\hline watch & B & 1 & 780 & 1 & 3 & 3.714 & 1 & 14511 \\
\hline wheel & A & 1 & 913 & 1 & 4 & 3.807 & 3 & 22753 \\
\hline window & B & 1 & 822 & 2 & 5 & 5.303 & 1 & 26944 \\
\hline MEAN & - & 0.9812 & 872.57 & 1.550 & 4.017 & 3.211 & 1.983 & 16305.4 \\
\hline
\end{tabular}


APPENDIX B

Means for Sets A and B of List 2 with associated $t$-tests

\begin{tabular}{lcccc}
\hline Variable & Set $A$ & Set $B$ & $t=$ & $p=$ \\
\hline Name agreement & 0.9803 & 0.9820 & .382 & .745 \\
RT & 873.93 & 871.20 & .100 & .921 \\
Syllables & 1.6 & 1.5 & .711 & .483 \\
Phonemes & 4.13 & 3.90 & .814 & .422 \\
Frequency & 2.97 & 3.46 & 1.539 & .135 \\
AoA & 2.00 & 1.96 & .186 & .854 \\
Visual complexity & 17647.9 & 14962.9 & 1.789 & .084 \\
\hline
\end{tabular}

APPENDIX C

List 2 items and associated stimulus properties

\begin{tabular}{lcccccccc}
\hline Items & Set & $\begin{array}{c}\text { Name } \\
\text { agreement }\end{array}$ & Reaction time & Syllables & Phonemes & Frequency & AoA & $\begin{array}{c}\text { Visual } \\
\text { complexity }\end{array}$ \\
\hline apple & A & 1 & 810 & 2 & 3 & 3.434 & 1 & 8241 \\
balloon & B & 1 & 702 & 2 & 5 & 1.946 & 1 & 8015 \\
basket & A & 0.98 & 832 & 2 & 5 & 3.219 & 2 & 23651 \\
bat & B & 1 & 764 & 1 & 3 & 2.708 & 2 & 16687 \\
bone & A & 1 & 872 & 1 & 3 & 4.248 & 3 & 14370 \\
bottle & B & 0.9 & 956 & 2 & 4 & 4.762 & 1 & 6551 \\
bowl & A & 0.98 & 831 & 1 & 3 & 3.526 & 1 & 9408 \\
bus & B & 1 & 771 & 1 & 3 & 4.382 & 1 & 23164 \\
cake & A & 1 & 789 & 1 & 3 & 3.555 & 1 & 16237 \\
candle & B & 1 & 831 & 2 & 5 & 2.833 & 3 & 8385 \\
car & A & 1 & 751 & 1 & 2 & 5.872 & 1 & 9255 \\
cat & B & 0.96 & 766 & 1 & 3 & 4.22 & 1 & 9894 \\
chain & A & 1 & 943 & 1 & 3 & 3.892 & 3 & 12912 \\
cheese & B & 1 & 843 & 1 & 3 & 3.466 & 1 & 12988 \\
cigarette & A & 0.94 & 1016 & 3 & 7 & 4.277 & 3 & 7988 \\
dog & A & 1 & 702 & 1 & 3 & 4.754 & 1 & 12012 \\
dragon & A & 1 & 891 & 2 & 5 & 2.303 & 3 & 19272 \\
ear & B & 1 & 681 & 1 & 2 & 4.489 & 1 & 9033 \\
feather & A & 0.98 & 977 & 2 & 4 & 3.091 & 3 & 21626 \\
fish & B & 1 & 777 & 1 & 3 & 5.1 & 1 & 12019 \\
flower & A & 1 & 754 & 2 & 4 & 4.543 & 1 & 15082 \\
foot & B & 0.98 & 758 & 1 & 3 & 5.79 & 1 & 7638 \\
frog & A & 1 & 751 & 1 & 4 & 2.303 & 1 & 14773 \\
ghost & B & 1 & 849 & 1 & 4 & 3.466 & 3 & 23538 \\
girl & A & 0.92 & 861 & 1 & 3 & 6.084 & 1 & 15540 \\
guitar & B & 0.98 & 870 & 2 & 4 & 2.079 & 3 & 12032 \\
hair & A & 0.98 & 999 & 1 & 2 & 5.298 & 1 & 41463 \\
harp & B & 0.96 & 914 & 1 & 3 & 1.386 & 3 & 14170 \\
horse & A & 1 & 809 & 1 & 3 & 4.89 & 1 & 18397 \\
iron & B & 1 & 856 & 2 & 3 & 4.277 & 3 & 16843 \\
\hline & & & & & & & & $($ Cont \\
\hline
\end{tabular}

(Continued) 
APPENDIX C

(Continued)

\begin{tabular}{|c|c|c|c|c|c|c|c|c|}
\hline Items & Set & $\begin{array}{c}\text { Name } \\
\text { agreement }\end{array}$ & Reaction time & Syllables & Phonemes & Frequency & $A o A$ & $\begin{array}{c}\text { Visual } \\
\text { complexity }\end{array}$ \\
\hline $\begin{array}{l}\text { ironing } \\
\text { board }\end{array}$ & $\mathrm{B}$ & 0.9 & 1105 & 4 & 8 & 0 & 3 & 12848 \\
\hline jacket & $\mathrm{B}$ & 0.92 & 881 & 2 & 5 & 3.761 & 1 & 30351 \\
\hline key & A & 1 & 738 & 1 & 2 & 4.466 & 1 & 7493 \\
\hline king & $\mathrm{B}$ & 1 & 898 & 1 & 3 & 4.605 & 3 & 31165 \\
\hline lemon & A & 0.96 & 911 & 2 & 5 & 2.773 & 3 & 8524 \\
\hline match & $\mathrm{B}$ & 1 & 910 & 1 & 3 & 4.06 & 3 & 13078 \\
\hline mouse & A & 0.92 & 961 & 1 & 3 & 2.944 & 1 & 13250 \\
\hline nail & $\mathrm{B}$ & 1 & 1086 & 1 & 4 & 3.258 & 2 & 9585 \\
\hline orange & $\mathrm{A}$ & 0.96 & 1098 & 2 & 5 & 3.045 & 1 & 10314 \\
\hline pear & B & 1 & 949 & 1 & 2 & 1.946 & 3 & 18960 \\
\hline pen & A & 1 & 753 & 1 & 3 & 3.296 & 1 & 9078 \\
\hline pineapple & B & 0.98 & 871 & 3 & 6 & 1.386 & 3 & 20721 \\
\hline pumpkin & $\mathrm{A}$ & 1 & 909 & 2 & 7 & 1.099 & 2 & 18960 \\
\hline pyramid & $\mathrm{B}$ & 0.98 & 987 & 3 & 7 & 2.079 & 3 & 19838 \\
\hline rake & A & 0.98 & 828 & 1 & 3 & 1.099 & 3 & 5156 \\
\hline rocket & A & 0.9 & 854 & 2 & 5 & 2.708 & 3 & 18164 \\
\hline rope & A & 1 & 810 & 1 & 3 & 3.761 & 3 & 34568 \\
\hline shark & $\mathrm{B}$ & 0.96 & 1014 & 1 & 3 & 3.045 & 3 & 14311 \\
\hline sink & A & 0.96 & 984 & 1 & 4 & 2.773 & 1 & 26560 \\
\hline skeleton & $\mathrm{B}$ & 1 & 817 & 3 & 8 & 2.565 & 3 & 10724 \\
\hline skunk & A & 0.98 & 1044 & 1 & 5 & 0 & 3 & 16683 \\
\hline spoon & $\mathrm{B}$ & 1 & 777 & 1 & 4 & 2.773 & 1 & 7344 \\
\hline tiger & B & 0.91 & 1072 & 2 & 4 & 2.565 & 1 & 45476 \\
\hline toaster & & 0.96 & 860 & 2 & 5 & 0.693 & 3 & 13290 \\
\hline toilet & A & 1 & 825 & 2 & 5 & 3.367 & 3 & 22049 \\
\hline train & $\mathrm{B}$ & 1 & 838 & 1 & 4 & 4.407 & 1 & 18361 \\
\hline unicorn & A & 1 & 928 & 3 & 7 & 0.693 & 3 & 12749 \\
\hline well & $\mathrm{B}$ & 0.96 & 991 & 1 & 3 & 1.792 & 3 & 12965 \\
\hline whistle & A & 1 & 790 & 2 & 4 & 2.303 & 3 & 10521 \\
\hline witch & $\mathrm{B}$ & 1 & 879 & 1 & 3 & 3.497 & 3 & 27723 \\
\hline MEAN & - & 0.9798 & 871.57 & 1.533 & 3.967 & 3.216 & 2.033 & 16033.2 \\
\hline
\end{tabular}

\section{APPENDIX D}

Means for Sets A and B of List 2 with associated $t$-tests

\begin{tabular}{lcccc}
\hline Variable & Set $A$ & Set $B$ & $t=$ & $p=$ \\
\hline Name agreement & 0.9813 & 0.9783 & .582 & .565 \\
RT & 867.4 & 875.8 & .455 & .653 \\
Syllables & 1.5 & 1.6 & .580 & .566 \\
Phonemes & 3.93 & 4.00 & .258 & .798 \\
Frequency & 3.32 & 3.11 & .797 & .432 \\
AoA & 1.93 & 2.13 & 1.117 & .273 \\
Visual complexity & 15809.9 & 16256.6 & .304 & .763 \\
\hline
\end{tabular}


APPENDIX E

List 3 items and associated stimulus properties

\begin{tabular}{|c|c|c|c|c|c|c|c|c|}
\hline Items & Set & $\begin{array}{c}\text { Name } \\
\text { agreement }\end{array}$ & Reaction time & Syllables & Phonemes & Frequency & AoA & $\begin{array}{c}\text { Visual } \\
\text { complexity }\end{array}$ \\
\hline arrow & $\mathrm{A}$ & 0.98 & 785 & 2 & 3 & 2.773 & 3 & 5990 \\
\hline ball & B & 1 & 886 & 1 & 3 & 4.718 & 1 & 13345 \\
\hline banana & $\mathrm{A}$ & 1 & 808 & 3 & 6 & 2.197 & 1 & 8767 \\
\hline belt & B & 1 & 812 & 1 & 4 & 3.296 & 2 & 18762 \\
\hline bench & $\mathrm{A}$ & 0.94 & 896 & 1 & 4 & 3.178 & 2 & 25379 \\
\hline box & B & 1 & 753 & 1 & 4 & 4.635 & 1 & 18074 \\
\hline bread & A & 0.98 & 773 & 1 & 4 & 4.317 & 1 & 10161 \\
\hline bridge & B & 0.98 & 862 & 1 & 4 & 4.205 & 3 & 27543 \\
\hline camel & A & 1 & 892 & 2 & 4 & 3.258 & 3 & 26026 \\
\hline camera & $\mathrm{B}$ & 1 & 725 & 3 & 5 & 3.611 & 2 & 16408 \\
\hline carrot & A & 1 & 806 & 2 & 5 & 2.197 & 1 & 13201 \\
\hline clock & $\mathrm{B}$ & 0.98 & 772 & 1 & 4 & 3.689 & 1 & 25639 \\
\hline cross & $\mathrm{A}$ & 1 & 793 & 1 & 4 & 3.135 & 3 & 9790 \\
\hline crown & B & 0.94 & 945 & 1 & 4 & 3.219 & 3 & 23655 \\
\hline desk & $\mathrm{A}$ & 1 & 975 & 1 & 4 & 4.522 & 3 & 17761 \\
\hline dolphin & B & 0.98 & 894 & 2 & 6 & 1.386 & 3 & 9949 \\
\hline drawer & A & 1 & 994 & 2 & 3 & 3.219 & 1 & 16141 \\
\hline dress & B & 1 & 840 & 1 & 4 & 4.477 & 1 & 23619 \\
\hline elephant & $\mathrm{A}$ & 0.98 & 837 & 3 & 7 & 3.219 & 1 & 24585 \\
\hline eye & B & 0.98 & 700 & 1 & 1 & 6.261 & 1 & 9104 \\
\hline fence & $\mathrm{A}$ & 0.98 & 819 & 1 & 4 & 3.434 & 3 & 17349 \\
\hline fly & B & 0.9 & 1080 & 1 & 3 & 3.611 & 3 & 11935 \\
\hline globe & B & 0.98 & 883.00 & 1 & 4 & 2.485 & 3 & 24454 \\
\hline glove & A & 1 & 848 & 1 & 4 & 2.996 & 3 & 11509 \\
\hline hand & B & 0.98 & 723 & 1 & 4 & 6.586 & 1 & 13345 \\
\hline helicopter & A & 1 & 793 & 4 & 9 & 2.833 & 2 & 18241 \\
\hline hose & B & 0.96 & 983 & 1 & 3 & 1.609 & 2 & 26130 \\
\hline igloo & B & 1 & 963 & 2 & 4 & 0.693 & 3 & 9673 \\
\hline knife & B & 1 & 816 & 1 & 3 & 3.807 & 2 & 8773 \\
\hline ladder & A & 1 & 988 & 2 & 4 & 2.833 & 2 & 25701 \\
\hline lamp & $\mathrm{A}$ & 0.92 & 835 & 1 & 4 & 3.584 & 1 & 13522 \\
\hline leaf & $\mathrm{A}$ & 1 & 848 & 1 & 3 & 4.407 & 3 & 26600 \\
\hline lightbulb & $\mathrm{A}$ & 0.92 & 737 & 2 & 7 & 0 & 3 & 10034 \\
\hline lipstick & $\mathrm{A}$ & 1 & 803 & 2 & 7 & 2.079 & 3 & 6029 \\
\hline $\operatorname{man}$ & $\mathrm{A}$ & 0.94 & 978 & 1 & 3 & 7.396 & 1 & 15791 \\
\hline map & $\mathrm{A}$ & 1 & 847 & 1 & 3 & 3.714 & 3 & 41029 \\
\hline mask & B & 0.98 & 852 & 1 & 4 & 3.045 & 3 & 13646 \\
\hline monkey & $\mathrm{A}$ & 1 & 794 & 2 & 5 & 2.944 & 1 & 18988 \\
\hline moon & B & 1 & 804 & 1 & 3 & 4.094 & 1 & 3730 \\
\hline mop & A & 0.94 & 933 & 1 & 3 & 1.386 & 2 & 14393 \\
\hline mountain & B & 0.94 & 921 & 2 & 6 & 4.443 & 3 & 13588 \\
\hline nose & A & 1 & 721 & 1 & 3 & 4.407 & 1 & 4703 \\
\hline nurse & B & 0.96 & 1039 & 1 & 3 & 3.912 & 2 & 19385 \\
\hline onion & A & 0.94 & 1100 & 2 & 5 & 2.833 & 3 & 11645 \\
\hline piano & B & 1 & 798 & 3 & 5 & 3.332 & 3 & 19570 \\
\hline pipe & A & 0.98 & 866 & 1 & 3 & 3.466 & 3 & 7235 \\
\hline razor & B & 0.94 & 1089 & 2 & 4 & 2.303 & 3 & 14404 \\
\hline ring & B & 1 & 785 & 1 & 3 & 1.386 & 3 & 7652 \\
\hline robot & $\mathrm{B}$ & 0.98 & 793 & 2 & 5 & 2.079 & 3 & 9502 \\
\hline
\end{tabular}


APPENDIX E

(Continued)

\begin{tabular}{|c|c|c|c|c|c|c|c|c|}
\hline Items & Set & $\begin{array}{c}\text { Name } \\
\text { agreement }\end{array}$ & Reaction time & Syllables & Phonemes & Frequency & AoA & $\begin{array}{c}\text { Visual } \\
\text { complexity }\end{array}$ \\
\hline roof & A & 0.94 & 1094 & 1 & 3 & 4.043 & 2 & 13178 \\
\hline saddle & A & 1 & 1019 & 2 & 4 & 2.398 & 3 & 10307 \\
\hline saw & A & 1 & 863 & 1 & 2 & 0.693 & 3 & 11302 \\
\hline slide & B & 1 & 1003 & 1 & 4 & 2.565 & 1 & 20613 \\
\hline snake & B & 1 & 775 & 1 & 4 & 3.178 & 3 & 23761 \\
\hline sun & $\mathrm{A}$ & 1 & 762 & 1 & 3 & 5.03 & 1 & 18102 \\
\hline table & B & 0.98 & 852 & 2 & 4 & 5.464 & 1 & 12010 \\
\hline typewriter & B & 1 & 778 & 3 & 7 & 2.485 & 3 & 28850 \\
\hline whale & $\mathrm{B}$ & 0.96 & 1050 & 1 & 4 & 2.485 & 3 & 15429 \\
\hline wig & A & 0.94 & 933 & 1 & 3 & 2.639 & 3 & 22371 \\
\hline zebra & B & 1 & 864 & 2 & 5 & 1.099 & 2 & 36034 \\
\hline MEAN & - & 0.9800 & 869.67 & 1.500 & 4.117 & 3.255 & 2.183 & 16573.5 \\
\hline
\end{tabular}

\section{APPENDIX F}

Means for Sets A and B of List 3 with associated $t$-tests

\begin{tabular}{lcccc}
\hline Variable & Set $A$ & Set $B$ & $t=$ & $p=$ \\
\hline Name agreement & 0.9793 & 0.9807 & .256 & .800 \\
RT & 871.3 & 868.0 & .182 & .857 \\
Syllables & 1.57 & 1.43 & .944 & .353 \\
Phonemes & 4.2 & 4.1 & .576 & .569 \\
Frequency & 3.17 & 3.34 & .680 & .502 \\
AoA & 2.17 & 2.2 & .200 & .843 \\
Visual complexity & 15861.0 & 17286.1 & .980 & .335 \\
\hline
\end{tabular}

\section{APPENDIX G}

Means for Lists 1-3 with associated $t$-tests

\begin{tabular}{lccccccccc}
\hline Variable & List 1 mean & List 2 mean & List 3 mean & $1-2 t$ & $1-2 p$ & $2-3 t$ & $2-3 p$ & $1-3 t$ & $1-3 p$ \\
\hline Name agreement & 0.9812 & 0.9798 & 0.98 & .367 & .715 & .043 & .966 & .313 & .755 \\
RT & 872.57 & 871.57 & 869.67 & .058 & .954 & .141 & .888 & .168 & .867 \\
Syllables & 1.550 & 1.533 & 1.500 & .182 & .856 & .357 & .723 & .536 & .594 \\
Phonemes & 4.017 & 3.967 & 4.117 & .231 & .818 & .791 & .432 & .468 & .642 \\
Frequency & 3.211 & 3.216 & 3.255 & .027 & .978 & .217 & .829 & .229 & .820 \\
AoA & 1.983 & 2.033 & 2.183 & .399 & .692 & 1.191 & .239 & 1.602 & .114 \\
Visual complexity & 16305 & 16033 & 16574 & .262 & .794 & .504 & .616 & .258 & .797 \\
\hline
\end{tabular}

